\title{
ULISSES INDECISO : POSSIBILIDADES E LIMITES DO INDIVIDUALISMO METODOLÓGICO NA OBRA DE JON ELSTER
}

\author{
Samuel Martins dos Santos ${ }^{1}$
}

Resumo: O artigo enfoca o individualismo metodológico de Jon Elster e suas análises a respeito dos pré-compromissos constitucionais. O problema do trabalho diz respeito as possibilidade e limites da opção metodológica do autor para este debate no contexto dos regimes políticos democráticos. Para tanto, o texto analisa revisões feitas pelo próprio autor no decorrer da sua obra, como também objeções e críticas desenvolvidas a partir do referencial da Teoria Democrática contemporânea.

Palavras-chave - Pré-compromisso; Constituição; Democracia; Metodologia

\section{ULISSES UNDECIDED : POSSIBILITIES AND LIMITS OS METHODOLOGICAL INDIVIDUALISMO IN JOHN ELSER'S.}

\begin{abstract}
The article focuses on the methodological individualism of Jon Elster and his analysis of constitutional pre-commitment. The problem of work concerns the possibilities and limits of the author's methodological choice for this debate in the context of democratic political regimes. Thus, the text indicates the revisions made by the author himself, in the recognition of the limits of his initial option, as well as objections and criticisms presented by authors closer to the contemporary Democratic Theory.
\end{abstract}

Keywords: Methodology - Constitution - Pre-commitment - Democracy

\section{Introdução}

O artigo tem como objeto a obra de Jon Elster, particularmente, sua opção metodológica e análises a respeito das relações entre o pré-compromisso constitucional e a democracia.

\footnotetext{
*Samuel Martins dos Santos é Mestre em Teoria e Filosofia do Direito pela Universidade Federal de Santa Catarina, professor de Direito Constitucional da Faculdade CESUSC e coordenador do Grupo Constituição, democracia \& direitos fundamentais. Email: samuel@wohlkemartins.com.br. Endereço postal - Rua Adhemar da Silva, 826, Bairro Kobrassol. Sâo José, Santa Catarina, CEP. 88.101-091.
} 
O problema que serve de direcionamento deste trabalho pode ser formulado da seguinte maneira: Quais são as possibilidades e os limites do individualismo metodológico de Jon Elster para a solução de questões sobre pré-compromisso constitucional e democracia?

A resposta à este questionamento será buscada na obra de Jon Elster, posteriormente apresentaremos algumas objeções à sua opção metodológica que podem ser elaboradas a partir de referenciais teóricos da Teoria Democrática contemporânea,

Inicialmente vale recortar que os denominados pré-compromissos constitucionais são mecanismos criados em momentos de elaboração de uma Constituição, a sua principal característica é conter elementos decisórios fundamentais que não poderão ser objeto de deliberação posterior.

Conforme estudaremos, tais pré-compromissos podem ser de conteúdo, ou de caráter procedimental, por exemplo, quando o processo legislativo de alteração de uma norma constitucional se apresenta mais dificultoso do que um processo legislativo comum ordinário.

Os principais elementos a respeito dos pré-compromissos constitucionais que são debatidos por Jon Elster e inúmeros outros autores (HOLMES; 2014; WALDRON, 2005) dizem respeito aos riscos de limitação por uma decisão do passado em relação ao presente, como também a supressão de pautas que poderiam ser debatidas e decididas em deliberações democráticas.

Em sentido mais amplo, o panorama institucional no qual estas instituições estão inseridas são as possibilidades de mudanças constitucionais sem passagem por processos revolucionários. Isto porque a depender da extensão, e dos limites, dos pré-compromissos constitucionais, mesmo que se obtenha um grande consenso absolutamente majoritário a respeito da necessidade de mudanças institucionais, ainda neste contexto o pré-compromisso seria uma obstrução jurídica à esta possibilidade de mudança.

A atualidade deste debate para os Estados contemporâneos é por demais evidente, conforme exemplificaremos a seguir. O Brasil foi palco de grandes manifestações no ano de 2013, em larga medida os temas que circularam como mais relevantes expressavam uma grande insatisfação com o funcionamento do Estado, a qualidade da prestação dos serviços públicos, e também com o sistema político. À época, a então titular do Poder Executivo, Sra. Dilma Rousseff, fez uma proposta de criação de uma Assembleia Nacional Constituinte Exclusiva e Parcial. 


\section{ULISSES INDECISO : POSSIBILIDADES E LIMITES DO INDIVIDUALISMO METODOLÓGICO NA OBRA DE JON ELSTER}

Independentemente de analisar o mérito da proposta, como também o seu potencial de solução daquela crise política. Importa destacar que entre os constitucionalistas a discussão se centrou na existência, ou não, de possibilidade institucional de tal proposta nos termos da Constituição da República Federativa do Brasil de 1988.

Tal debate diz respeito a adequação do modelo instituído em 1988 em relação a estas demandas do presente, isto é, se os pré-compromissos assumidos naquela Assembleia Nacional Constituinte do passado seriam limitadores, ou facilitadores, destas demandas do presente.

Ainda no Brasil, destaca-se a posição pacificada do Supremo Tribunal Federal de não analisar a constitucionalidade do texto constitucional originário de 1988, nos termos da ADI 815/DF.. Tal posição fortalece a força normativa dos pré-compromissos constitucionais, isto porque impede a apreciação de tais normais pelo Poder Judiciário, e com isto a possibilidade de mutação constitucional, ou declaração de inconstitucionalidade expressa, ficam afastadas.

Em inúmeros outros países também é possível apontarmos debates nos quais decisões fundamentais consideradas como imutáveis foram objeto de grande discussão sobre a possibilidade de sua modificação, seja no âmbito do constitucionalismo latino-americano, como também nos debates a respeito das mudanças da Constituição da República Portuguesa de 1976.

Considerando a alta complexidade das sociedades contemporâneas no final do século XX e início do século XXI, é previsível que tais questionamentos terão um aumento da sua importância, do que se justificam análises como a proposta no presente texto.

$\mathrm{Na}$ primeira parte do artigo analisaremos os pontos básicos do iindividualismo metodológico de Jon Elster, para posteriormente verificarmos como tal metodologia condiciona suas respostas ao debate sobre as relações entre o pré-compromisso constitucional e democracia.

Na segunda parte do texto, apresentaremos críticas e objeções às análises de Jon Elster com o objetivo de averiguar as possibilidades e os limites do seu individualismo metodológico para tal debate.

\section{$2 \mathrm{O}$ individualismo metodológico e Ulisses}

Os trabalhos de Jon Elster a respeito do pré-compromisso constitucional datam do final da década de 70, quando foi publicado o ensaio Ulisses e as sereias, posteriormente o mesmo foi revisto pelo autor, do que resultou a publicação da obra Ulisses Liberto no ano 2000. 
Exporemos a posição inicial do autor, para depois apresentar os elementos da sua autocrítica, a questão apresentada por Jon Elster diz respeito a imposição de limites que as pessoas fazem a si mesmas.

O trabalho do autor é fortemente marcado pela defesa de uma opção metodológica específica, o seu ponto de partida é a crítica às práticas nas ciências sociais que compõem explicações ao desenvolvimento de instituições sociais e jurídicas a partir de nexos de causalidade que se apresentam como passíveis de objeção. Assim, as ciências sociais apresentariam fragilidade no seu potencial explicativo do surgimento e desenvolvimento das instituições, denominadas de mecanimos pelo autor. As suas críticas as explicações comumente desenvolvidas nas ciências sociais possuem a seguinte base:

- $\quad$ Explicações causais devem ser distinguidas de proposições causais verdadeiras

- $\quad$ Explicações causais devem ser distinguidas de afirmações sobre correlação

- $\quad$ Explicações causais devem ser distinguidas sobre afirmações sobre necessitação. (ELSTER, 1994, p. 17-20)

A partir desta perspectiva, Jon Elster apresenta sua proposta conhecida como individualismo metodológico, segundo a qual a referêcia principal para a explicação dos fenômenos sociais deve ser o indivíduo, ao invés das coletividades e das instituições. Assim, é a ação humana, e a interação entre os sujeitos, que possuem maior potencial explicativo dos mecanismos sociais.

O enfoque ao comportamento do indivíduo, antes de refletir sobre a coletividade, está relacionado a metodologia desenvolvida pelo autor que é caracterizada pela preponderância da análise da ação dos indivíduos como uma referência também para a compreensão do comportamento das coletividades, como se este segundo objeto fosse um desdobramento das ações individuais:

Um dos traços mais marcantes da filosofia das ciências sociais de John Elster (1985) é a sua defesa permanente e fiel do individualismo metodológico. Para 


\section{ULISSES INDECISO : POSSIBILIDADES E LIMITES DO INDIVIDUALISMO METODOLÓGICO NA OBRA DE JON ELSTER}

ele, trata-se de uma doutrina em que todos os fenômenos sociais - sua estrutura e sua mudança -são, em princípio, explicáveis de forma que somente envolvam indivíduos - suas propriedades, seus objetivos, suas crenças e suas ações. (JUNIOR, MORAIS, 2003, p. 384-385),

Tal informação é relevante por se tratar de um método essencial para a compreensão da figura do Ulisses, da auto-critica que o autor fez posteriormente, como também das críticas que recebeu em relação ao seu texto originário. Em função do individualismo metodológico, a perspectiva inicial de Elster é o indivíduo, para, apenas posteriormente, o mesmo fazer a relação entre a sua análise individual e a sociedade.

A opção metodológica de Jon Elster indica um ponto fulcral na Teoria Social e também no estudo do Direito Constitucional, tal debate é composto pela polarização de analistas do indivíduo, que concebem a sociedade como um macrocosmo do comportamento deste, e, por outro lado, autor que identificam na coletividade um comportamento social diferenciado do que a simples projeção do comportamento do indivíduo.

O primeiro caso, enfocado no indivíduo possuí atualmente uma inegável influência da Teoria Liberal, sendo que as perspectivas coletivistas, também denominada de holismo metodológico, remontam suas análises às obras de Aristóteles, entre outros.

O trabalho no qual Jon Elster levou mais a efeito a defesa do individualismo metodológico foi publicado no Brasil com o título Peças e engrenagens das ciências sociais (1994), segundo a Argelina Cheiub Figueiredo os pontos fundamentais da Filosofia da Ciência do autor são os seguintes:

Primeiro, a premissa do individualismo metodológico, ou seja, de que os fenômenos sociais (sua estrutura e suas mudanças) são explicáveis apenas em termos dos indivíduos: de suas características, de seus fins e de suas crenças. A ação individual é a unidade elementar da vida social. Os fenômenos sociais resultam da ação e da interação entre indivíduos. (...) Para Elster, as Ciências Sociais devem oferecer explicações intencionais-causais, ou seja, a explicação intencional das ações individuais juntamente com a explicação causal da interação entre os indivíduos. (FIGUEIREDO, 1994, p. 7). 
Uma contribuição inegável da proposta metodológica de Jon Elster encontra-se na indicação da necessidade de prevenção em relação a metas-narrativas que maximizam o protagonismo das coletividades, e deixam em segundo plano os elementos motivadores e inibidores da ação individual.

No mesmo sentido, outra contribuição relevante do individualismo metodológico faz referencia à uma maior problematização em relação aos nexos de causalidade nas ações sociais, forçando assim o analista à um maior critério metodológico.

A ênfase analítica de Jon Elster sobre o indivíduo tem como objeto a explicação do fenômeno social em sua permanência e repetição, mas também inclui o elemento mudança social como um objeto a ser pesquisado.

E neste ponto, o seu trabalho se aproxima das discussões entre o pré-compromisso e a democracia, visto que o primeiro comumente é reconhecido como um empecilho à mudança social, por decorrência de decisões fundamentais previamente tomadas.

Nas suas análises sobre a possibilidade de mudança institucional e social, o autor enfocará a Constituições por considerá-las elementares às sociedades democráticas contemporâneas. Deste modo, a partir de uma perspectiva moral, o autor pretende analisar o quando os pré-compromissos constitucionais instituídos nestes documentos fundantes são impeditivos de mudanças institucionais posteriores:

Estoy enfocando constituciones por que son la encarnación de la legitimidade em casi todas las sociedades democraticas. Podrá objertarse que las constituciones son sólo los restos accidentales del passado, que não devem obstaculizar la formación del futuro. Aunque em um sentido esta afirmación, sea indiscutiblemente certa, em outro vá desencaminhada. Uma Constituición obtiene legitimidade partiendo de lo que se há llamado ‘el poder normativo de lo fáctico’: comparada con las opciones que están contendiendo com lo status quo y también entre si, tiene el privilegio de existir. Sin embargo, em lá objción hay este importante meollo de verdade: no devemos sentirmos obligados, o ao menos esto aduciré, por uma Constituición que haga imposible el cambio. (ELSTER, 1999, p. 323).

Com isto o debate está posto, a partir do aporte metodológico do autor para análise dos fenômenos e das mudanças sociais, como também da relevância do documento constitucional 


\section{ULISSES INDECISO : POSSIBILIDADES E LIMITES DO INDIVIDUALISMO METODOLÓGICO NA OBRA DE JON ELSTER}

para o autor como uma instituição com possibilidade de estabelecer pré-compromissos sem impedir as mudanças sociais.

Neste trabalho enfocaremos os argumentos que o autor aponta para justificar a existência dos pré-compromissos que são aplicáveis tanto a indivíduos como para sociedades. A pergunta que serve de diretriz ao seu trabalho diz respeito às razões que levam as pessoas a criarem restrições para si próprias. No desenvolvimento da sua análise, o autor utiliza-se de uma metáfora por demais conhecida.

Ulisses é o capitão de um navio, que tem no seu percurso a passagem por uma ilha na qual os cânticos das sereias convidavam todos os navegantes à aproximação, ocorre que a ilha se encontra rodeada por perigos e rochedos, de modo que a aproximação invariavelmente tinha como consequência o fracasso, com o afundamento do navio. Visando evitar tal perigo, Ulisses pede aos seus marinheiros que o amarrem e coloquem cera nos seus ouvidos, para impedi-lo de ouvir o canto das serias, e ordena aos seus marinheiros que por mais que ele determine à aproximação junto a ilha no decorrer da viagem, que ele não seja ouvido.

Tal composição narrativa é utilizada para debater quais são as vantagens e desvantagens dos indivíduos e das coletividades se imporem auto-restrições. Neste aspecto o autor apresenta o que ele denomina de Teoria da Restrição: "o que o livro analisa são as restrições que se traduzem em tornar as opções conhecidas menos disponíveis, em vez de bloquear o conhecimento da sua existência.” (ELSTER, 2009, p. 14 -15).

A argumentação é desenvolvida no sentido de indicar que a restrição às possibilidades de ação pode significar um aumento no potencial de organização da ação do indivíduo, e que tal perspectiva é aperfeiçoada quando ocorre o distanciamento da concepção de que o maior número de possibilidades de ação é o melhor para o indivíduo e as coletividades. Inversamente, o autor defende que um menor número de opções à ação pode causar menos insegurança no processo de tomada de decisão, o que já implica por si uma maior agilidade, como também mais eficiência na busca de estabilidade.

No desenvolvimento da sua obra, John Elster apresenta elementos que podem constituir instabilidades para os regimes políticos, de modo a colocar em questão decisões anteriormente tomadas, como a paixão e a inconsistência temporal. Tais elementos são apresentados como possibilidades de alteração das determinações iniciais, seja um indivíduo, ou seja uma coletividade, a característica da condição humana como suscetível de ser tomada 
por sentimentos como as paixões pode causar significativas alterações na capacidade de autorestrição por parte dos indivíduos e das coletividades:

Quando agimos sob a influência das paixões, elas podem fazer que nos desviemos dos planos traçados em um momento mais tranquilo. $\mathrm{O}$ conhecimento dessa tendência cria um incentivo para que nos précomprometamos a não nos desviar de nossos plenos originais. Aqui, utilizo o termo ‘paixão’ em um sentido amplo, que abrange não apenas as emoções típicas como a raiva, medo, amor, vergonha e outras, mas também estados como intoxicação alcóolica, desejo sexual, desejo de drogas que criam dependência, dor e outros sentimentos viscerais. (ELSTER, 2009, p.19)

Neste ponto o trabalho do autor apresenta potencial para significativa contribuição nas pesquisas da seara do Direito Constitucional, isto porque o desenvolvimento de análises neste campo das Ciências Sociais Aplicadas é caracterizado pela predominância de critérios racionalistas em relação ao comportamento dos indivíduos, como também das coletividades.

Nos mais variados aspectos, o paradigma analítico do comportamento dos governantes, da sua relação com os cidadãos e do comportamento destes em relação a processos decisórios é a racionalidade moderna. No entanto, análises de Direito Constitucional com perspectivas descritivas e realistas não podem desconsiderar que o projeto jurídico da modernidade não conseguiu excluir absolutamente os comportamentos não racionais dos processos políticos.

Com isto, o autor vai polarizar o momento de formulação da auto-restrição por parte do indivíduo, que pode se constituir como um pré-compromisso constitucional para as coletividades, e que podemos denominar de T1, do momento no qual esta coletividade encontrase tomada por paixões, que podemos denominar de T2, que podem questionar a decisão anteriormente tomada, a partir de elementos menos racionais e mais emotivos:

Para Elster, emoções são um tópico negligenciado nas ciências sociais contemporâneas, especialmente nas versões tributárias dos 


\section{ULISSES INDECISO : POSSIBILIDADES E LIMITES DO INDIVIDUALISMO METODOLÓGICO NA OBRA DE JON ELSTER}

pressupostos antropológicos encontrados na teoria econômica e a clássica. Ele propõe então uma agenda teórica para a investigação das emoções na vida social: o papel destas na sustentação das normas sociais, o papel das normas sociais na regulação das emoções, as interconexões entre racionalidade e emoções (emoções podem ser consideradas mais ou menos racionais, a interferência suposta das emoções sobre a racionalidade ou o contrário e a possibilidade de planejamento na vida emocional) etc... (JUNIOR, MORAIS, 2003, p. 387)

As paixões são concebidas como elementos de instabilidade nos processos deliberativos, que podem alterar o comportamento dos indivíduos e das coletividades em relação as decisões anteriormente tomadas e que fazem parte da auto-restrição ou do précompromisso constitucional.

Na análise de Jon Elster a existência das paixões como elementos de instabilidade justifica a necessidade dos pré-compromissos, tal como a não menos famosa metáfora do indivíduo que vai à uma festa, mas não quer dirigir embriagado, ciente deste risco, antes de embriagar-se o mesmo dá a chave para o seu amigo para que ele não as entregue na hipótese de embriaguez.

Um segundo elemento de instabilidade dos pré-compromissos que o autor apresenta é denominada inconsistência temporal: “Ocorre quando a melhor política planejada atualmente para algum período futuro não é mais a melhor política quando o período chega.” (CUKIERMAN apud ELSTER, 2009, p. 40).

A inconsistência temporal se encontra diretamente relacionada a passagem do tempo, o que pode trazer instabilidades de duas ordens quando refletida a partir da discussão do précompromisso constitucional; I. no referente as mudanças que a própria passagem do tempo impõe aos indivíduos e as coletividades; II. O debate intergeracional, visto que as gerações substitutas não teriam sido consultadas a respeito do conteúdo do pré-compromisso constitucional.

Segundo o autor, as paixões e a inconsistência temporal são elementos que corroboram para a justificação do pré-compromisso constitucional, isto é, justamente o reconhecimento 
destas instabilidades indicam a pertinência da importância do pré-compromisso como elemento de garantia da estabilidade dos regimes políticos.

Com vistas a diminuir a intensidade destas instabilidades Jon Elster vai apresentar um conjunto de métodos que podem fortalecer o papel desempenhado pelos pré-compromissos, tais quais a criação de recompensas na hipótese de manutenção da auto-restrição, a criação de atrasos de decisões que possam impactar o conteúdo do pré-compromisso, como forma de diminuir a influência das paixões e o fortalecimento das crenças que corroboram para a manutenção das auto-restrições.

A transposição das análises dos comportamentos individuais para o estudo de comportamentos coletivos foi identificada pelo Jon Elster como um ponto carente de revisão, que vai implicar em mudanças da obra originária Ulisses e as sereias para a obra revista Ulisses Liberto: “Como em muitos casos, transferir conceitos para estudar indivíduos para o comportamento de coletividades, como se estas fossem indivíduos em escala ampliada, pode ser enganoso..” (ELSTER, 2009, p. 124).

Vale ressaltar que em 1999 o Jon Elster já identificava os limites do seu individualismo metodológico:

Entretanto, a analogia entre a auto-imposição individual e a autoimposição política de limites é extremamente restrita. Um indivíduo pode comprometer-se com determinadas ações, ou, pelo menos, tornar mais difícil e menos provável desviar-se delas, recorrendo a uma estrutura legal externa e independente de si próprio. Mas não existe nada externo à sociedade. Com exceção de alguns casos especiais, como a abdicação de poderes ao FMI, as sociedades não podem confiar sua vontade a estruturas fora do seu próprio controle: os vínculos sempre podem ser desfeitos se as sociedades assim o desejarem. O problema não é explicar por que tantas constituições fracassam em impor obediência a seus criadores e nunca passam de meros pedaços de papel escrito. A questão está em compreender de que maneira muitas constituições conseguem adquirir essa misteriosa capacidade de serem obedecidas.”(ELSTER, 1999, p. 25).

Assim, a mudança de perspectiva da primeira edição da obra Ullises e as sereias (1999) para a obra revisada Ulisses Liberto (2009) é digna de nota, não porque o autor apresentava o individualismo metodológico como infalível, os seus limites são apontados desde suas obras 


\section{ULISSES INDECISO : POSSIBILIDADES E LIMITES DO INDIVIDUALISMO \\ METODOLÓGICO NA OBRA DE JON ELSTER}

iniciais, mas porque o limite identificado é caro ao debate constitucional, qual seja, a transposição de análises sobre indivíduos para análises sobre coletividades e sociedades.

Na obra revisada destaca-se uma ênfase no debate sobre de que modo o desenho constitucoinal impacta na formação e manutenção do pré-compromisso e como isto pode prevenir instabilidades à este regime político. Analisando o papel das Constituições escritas como institutos de aperfeiçoamento dos pré-compromissos constitucionais o autor indica os seguintes mecanismos que podem corroborar para a sua manutenção:

- $\quad$ A petrificação absoluta das leis;

- $\quad$ A adoção de uma maioria qualificada no Parlamento;

- A exigência de quórum maior do que para uma legislação ordinária;

- $\quad$ Os atrasos;

- $\quad$ A ratificação do Estado (em sistemas federais);

- $\quad$ A ratificação por referendo.

No caso da Constituição da República Federativa do Brasil é possível identificar como elementos constitutivos do pré-compromisso constitucional a instituição de um núcleo duro no sistema constitucional, como as cláusulas pétreas, previstas no art. 60, parágrafo 4, que impossibilita deliberações tendentes à abolir os direitos fundamentais, a forma de Estado, entre outros, como também a maior dificuldade do processo legislativo visando alterar a Constituição Federal.

No mesmo sentido, o autor indica que o bicameralismo é uma forma de resistência a impulsos de alteração de Constituição que possam ser identificados como violadores do précompromisso constitucional:

O pré-compromisso constitucional opera, portanto, em dois níveis. Em primeiro nível, a Constituição pode projetar a máquina de governo ordinária de forma a contrabalançar a paixão, superar a inconsistência temporal e promover a eficiência. Em nível mais elevado, a máquina de emendas da própria Constituição pode ser projetada para ser lenta e complicada. Essas restrições de alto nível têm dois efeitos. Por um lado, agem diretamente sobre os problemas da paixão, da inconsistência temporal e da eficiência. Por outro, garantem e 
estabilizam os mecanismos de primeiro nível que, por sua vez, agem sobre os mesmos problemas. (ELSTER, 2009, p. 154).

Por fim, vale indicar que o autor apresentará situações nas quais os pré-compromissos podem não ser desejáveis, como também podem não ser possíveis. A primeira hipótese ocorre quando os sujeitos responsáveis pela elaboração do pré-compromisso no T.1 encontram-se profundamente influenciados por elementos não justificáveis racionalmente, e de mero revanchismo contra outro grupo. Trata-se de uma questão relevante porque identifica uma séria objeção aos argumentos defensores do pré-compromisso, que supõem que no momento da sua elaboração, via de regra em Assembleias Nacionais Constituintes, os seus elaboradores encontram-se em uma situação mais elevada de deliberação racional, o que dificilmente ocorre em situações historicamente dadas: "Se as constituições são, em geral, escritas em tempos de crise, não é evidente que os constituintes estarão particularmente sóbrios. Aqueles que elaboraram a Constituição francesa de 1791, por exemplo, não eram famosos por sua sobriedade.” (ELSTER, 2009, p. 203).

No referente ao pré-compromisso não ser desejável, o debate volta-se à discussão sobre o eventual antagonismo entre Constituição e Democracia, caso a posição do grupo elaborador do texto originários seja pela preponderância da Democracia e de sua lógica majoritária, um pré-compromisso como um limitador desta deliberação pode não ser bem visto.

A auto-crítica que Jon Elster fará sobre a utilização do individualismo metodológico não ser suficiente para desconsiderar sua argumentação a respeito dos pré-compromissos constitucionais. Em que pese o próprio autor identifique inúmeros limites da sua proposta, percebe-se que a manutenção do pré-compromisso ainda é um elemento presente na sua análise, mesmo ciente de tantos limites decorrentes desta opção, na próxima parte do trabalho enfocaremos o conteúdo destas objeções e críticas.às propostas do autor.

\section{Ulisses indeciso e a democracia}

Na revisão da obra Ulisses e as sereias, conforme já assinalado, Jon Elsther indentifica que a transposição de comportamentos individuais para comportamentos coletivos é um ponto carente de maior análise.

Recapitulando, além do reconhecimento da tranpsoição indivíduo/coletividades como problemática, Jon Elster também indica que a dificuldade de verificação de um terceiro no 


\section{ULISSES INDECISO : POSSIBILIDADES E LIMITES DO INDIVIDUALISMO METODOLÓGICO NA OBRA DE JON ELSTER}

processo de tomada de decisão é outro ponto frágil da na sua análise. Isto porque na referência a Ulisses existem os marujos para fecharem seus ouvidos e o amarrarem ao mastro, em outro exemplo conhecido, da pessoa que vai à uma festa e sabe que vai se embriagar e não quer dirigir seu automóvel alcoolizado, também existe o amigo, um terceiro, que ficará responsável pela guarda das chaves e direção do automóvel se necessário for.

Ocorre que, como o próprio Jon Elster admite, em se tratando de sociedade não existe este terceiro a parte do risco iminente que pode servir como garante de que os pré-compromissos não serão rompidos.

Neste tópico abordaremos outras variáveis que não são expressamente tratadas pelo autor, ainda que se apresentem de grande relevância no debate sobre os pré-compromissos constitucionais nos regimes políticos democráticos.

A primeira questão está relacionada ao processo de decisão do Ulisses, que pede para que os seus comandados o amarrem e não lhe obedeçam quando ele ordenar a aproximação da embarcação das ilhas nas quais o canto das sereias ocorrem e a possibilidade do naufrágio é muito grande.

Nesta composição importa destacar que a figura do Ulisses não apresenta adequação com os modelos contemporâneos de Estados democráticos. A metáfora utilizada pelo autor é bastante clara ao indicar uma relação hierarquizada entre o comandante e os comandatos.

Na obra do Elster, a relação de obediência na embarcação é um elemento fundamental para o sucesso da sua argumentação e garantia de que não haverá nenhum tipo desobediência as suas ordens.

Se considerarmos que os regimes democráticos, em uma visão procedimentalista, são identificados como um processo institucional de tomada de decisão pelo povo a partir de parâmetros igualitários e majoritários, verificamos que a identificação com o povo ocorre em relação os comandados de Ulisses, e não com ele próprio. Na defesa do majoritarismo e dos processos decisórios democráticos Robert Dahl escreve:

Para começar, o domínio da maioria maximiza o número de pessoas que podem exercer a autodeterminação nas decisões coletivas. Em face dos limites de um sistema político em particular, da composição do demos e da necessidade de uma decisão coletiva sobre algum assunto. O princípio forte do domínio da maioria garante que o maior número possível de cidadãos viverá sob leis que escolheram para si próprios. (DAHL, 2012, p. 215-216). 
No caso em tela, podemos indicar dois pontos centrais a serem objeto de decisão, o primeiro referente a passar ou não passar pelas ilhas nas quais se encontram as sereias e o segundo referente ao procedimento para evitar a passagem. Temos, portanto, um précompromisso em sentido substantivo, fundado na decisão de não passar pelas ilhas e um précompromissos em sentido procedimental, que diz respeito ao procedimento para se evitar a passagem pelas ilhas, quais sejam, amarrar Ulisses e tapar seus ouvidos com mel.

A sua figura e a forma como Ullises decide a respeito dos pontos básicos desta questão aproxima-se mais de um líder autoritário com forte poder de coerção sobre os seus tripulantes, do que um líder democrático preocupado com o conteúdo e a forma do processo de tomada de decisão dentro da embarcação. Tal pressuposição decorre da ausência no texto de Jon Elster a alguma referência de natureza deliberativa entre Ulisses e seus comandados, como também da certeza do mesmo de que ele será obedecido.

Neste ponto, se não verificamos a construção de consensos apenas resta a possibilidade hipotética do uso da coerção para fazer com que as ordens sejam objeto de obediência.

Uma outra objeção possível ao potencial explicativo da metáfora utilizada por Jon Elster servir para análises de questões a respeito dos pré-compromissos nos regimes democráticos está relacionada a hipótese na qual Ulisses não tenha certeza sobre qual a melhor decisão para os casos em análises.

Tal problematização se apresenta como absolutamente cabível porque os regimes políticos democráticos são caracterizados por uma altíssima complexidade, e envolvem questões que nem sempre são passíveis de serem resolvidas de forma tão peremptória como na metáfora utilizada por Jon Elster.

Assim, a figura de um Ulisses indeciso é relevante para a reflexão destas situações mais complexas nas quais mais de uma posição pode se apresentar como defensável.

Um autor que desenvolve objeções diretas a partir desta perspectiva é Jeremy Waldron, que faz uma crítica contundente à metodologia aplicada por John Elster na metáfora sobre Ulisses e as Sereias, pois transpor de forma pouco problematizada um comportamento individual para analisar um comportamento coletivo apresenta fragilidades que são flagrantes. Conforme expõe Jeremy Waldron é preciso lembrar que em uma sociedade contemporânea 


\section{ULISSES INDECISO : POSSIBILIDADES E LIMITES DO INDIVIDUALISMO METODOLÓGICO NA OBRA DE JON ELSTER}

democrática, o papel de Ulisses é exercido pelo povo, em toda a sua pluralidade e em toda a sua complexidade nos processos decisórios:

La pluralid d uma comunidade política, la inevitable existência de diversidad de opiniones y desacuredos razonables entre sus miembros sobre todos los assuntos que conciernen a los derechos y la justicia y la dinâmica de la deliberación, tanto formal como informal, a lo largo del tempo; estas três cosas significan que raramente estamos em disposición de afirmar, con alguna seguridade, que la mayoria que apoya determinada posición em $\mathrm{t} 2$ represente la debilidade o el pánico que los que se oponían a este posición em t1 tenían razones para temer. (WALDRON, 2005, p323)

E este é um ponto fundamental para a compressão da posição de Jeremy Waldron a respeito do pré-compromisso, segundo o próprio, na medida em que todas constituições contemporâneas comportam algum tipo de mecanismo de reforma constitucional, como também limites procedimentais e materiais à estas reformas, sempre existirão dúvidas a respeito de qual o momento adequado para a reforma, e quais os limites à esta reforma.

A partir disto, Jeremy Waldron defende que o povo não possui esta possibilidade de manutenção da sua conviç̧ão de forma tão clara a ponto de justificar uma restrição da possibilidade deliberativa do presente em relação ao passado. O que representa uma forte objeção procedimental à existência do pré-compromisso, nos moldes apresentados por Jon Elster.

Finalizando este tópico, vale ressaltar que o debate sobre o processo de tomada de decisão do Ulisses, a forma de exercício da legitimidade da sua liderança, como também a respeitabilidade dos seus comandatos em relação ao seu líder são questõs centrais para que as justificativas que Jon Elster apresenta sobre os pré-compromissos sejam bem sucedidas.

\section{Considerações finais}

O presente artigo teve como objeto de análise o trabalho de Jon Elster, destacadamente, sua proposta a respeito do individualismo metodológico, e as consequências desta opção sobre a perspectiva do autor em torno da temática dos pré-compromissos constitucionais, visando identificar as possibilidades e os limites de tal metodologia para solucionar questões relevantes dos regimes políticos democráticos. 
Conforme foi exposto, o trabalho do autor possui inegável potencial contributivo na seara da metodologia das ciências sociais, possibilitando um aporte teórico metodológico para as análises sobre o funcionamento das instituições jurídicas.

Conforme o próprio autor admitiu em uma revisão da sua principal obra sobre o tema, a transposição do comportamento do indivíduo para análises de coletividades pode ser problemática, e a ausência de um terceiro garante do cumprimento dos pré-compromissos constitucionais na sociedade também indicam inegável pendência de maior aprofundamento.

Em uma perspectiva crítica à metáfora utilizada por Jon Elster, na perspectiva da Teoria Democrática contemporânea, destacamos análises de Robert Dahl e Jeremy Waldron, que possibilitam e apresentam objeções a processos deliberativos sem condicionantes democráticas, sejam procedimentais ou de legitimidade.

Conforme apresentamos no início deste trabalho, a visualização de dois 'pólos analíticos entre autores que enfatizam a ação do indivíduo, por um lado, e autores que enfocam as coletividades, por outro, tem grande potencial de análise para o Direito Constitucional. Sobretudo, porque a depender da opção metodológica dos autores podem resultar conclusões distintas.

As sociedades contemporâneas do século XXI são caracterizadas como sociedades multitudinárias, e processos deliberativos em larga escalas tendem a não ser compreendidos se o seu objeto de análise se restringem aos indivíduos, isto porque a coletividade também exerce um papel significativo de influência no comportamento individual, sendo realmente difícil identificar de forma peremptória qual é o sentido da preponderância nesta questão.

Neste ponto, a ênfase demasiada da análise de Jon Elsters na ação do indivíduo resta prejudicada para a compreensão de fenômenos de grande escala, se considerarmos eleitorados grandes, como é o caso do Brasil, é inegável que perspectivas holísticas também devem ser levadas em consideração no funcionamento das instituições. No entanto, mesmo quando trata de questões coletivas, a análise de JJon Elster persiste da perspectiva do individualismo metodológico, do que lhe resta inegável prejuízo.

Outro binômio relevante no presente trabalho, trata da relação entre pré-compromisso e democracia. A ênfase demasiada no pré-compromisso poderá significar um esvaziamento das possibilidades de deliberação democrática. Vale destacar, por fim, que para Jon Elster tal relação é de complementaridade e aperfeiçoamento, e não de limitação. (2009). 


\section{ULISSES INDECISO : POSSIBILIDADES E LIMITES DO INDIVIDUALISMO METODOLÓGICO NA OBRA DE JON ELSTER}

No entanto, a metáfora apresentada pelo autor não adequa-se facilmente à um processo deliberativo que apresente parâmetros mínimos de uma sociedade democrática. A figura de Ulisses, frente a adversidade, decide sozinho quanto ao procedimento para escapar do perigo, como também em relação ao mérito, de modo que sua decisão não apresenta uma alta legitimidade democrática.

Outra perspectiva que também pode indicar uma necessidade de revisão na metáfora utilizada por Jon Elster diz respeito à uma eventual indecisão por parte de Ulisses quanto ao melhor procedimento a ser adotado, situação absolutamente plausível em sociedades democráticas complexas, quando mais de uma solução pode ser igualmente defensável por pessoas bem intencionadas.

Efetivamente, questões de alta complexidade como os pré-compromissos em democracia contemporâneas não serão passíveis de solucionamento a partir da perspectiva de um único autor.

Assim podemos concluir que o trabalho de Jon Elster possui inegável contribuição metodológica, ainda que suas análises a respeito dos pré-compromissos constitucionais sejam carentes de maior aprofundamento nos regimes políticos democráticos.

\section{Referencias}

ARATO, Andrew. Construção constitucional e teorias da democracia. Lua Nova, São Paulo , n. 42, p. 5-51, 1997 Available from $<$ http://www.scielo.br/scielo.php?script=sci_arttext\&pid=S010264451997000300002\&lng=en \&nrm=iso>. Access on 22 June 2017. http://dx.doi.org/10.1590/S0102-64451997000300002.

DAHL, Robert. A democracia e seus críticos. Martins Fontes: São Paulo, 2012.

ELSTER, Jon. Peças e engrenagens das ciências sociais. Rio de Janeiro: Relume-Dumará, 1994.

SLAGSTAD, Rune. Constitucionalismo y democracia. Cidade do México: Fondo de Cultura Economica, 1999.

. A possibilidade da política racional. Rev. bras. Ci. Soc., São Paulo, v. 14, n. 39, p. 13-40, 1999 . Feb. Available from<http://www.scielo.br/scielo.php?script=sci_arttext\&pid=S010269091999000100002\&ln $\mathrm{g}=$ en\&nrm=iso $>$. access on 17 June 2017. 
São Paulo: Editroa UNESP, 2009.

FIGUEIREDO, Argelina Cheiub. Prefácio à edição brasileira. In: ELSTER, Jon. Peças e engrenagens das ciências sociais. Rio de Janeiro: Relume-Dumará, 1994, p. 7-12.

HOLMES, Stephen. Constituições e constitucionalismo, in ASENSI, Felipe. PAULA, Daniel Giotti de (orgs). Tratado de Direito Constitucional, vol. 2, Rio de Janeiro: Elsevier, 2014, 577-608.

JUNIOR, José Luiz de Amorin Ratton. MORAES, Jorge Ventura de. Para ler Jon Elster: Limites e possibilidades de explicação por mecanismos nas ciências sociais. In. Revista de Ciências Sociais - Dados. Vol. 46. Número 2. Rio de Janeiro: p. 385-410.

WALDRON, Jeremy. Derecho y desacuerdos. Madrid: Marcial Pons, 2005 A dignidade da legislação. São Paulo: Martins Fontes, 2003.

Univeristy Press, 2016.

Political Political Theory: essays on institutions. Cambridge: Harvard 